\title{
Anti-inflammatory and immunomodulatory properties of Pistacia lentiscus extracts
}

\author{
Hamama Bouriche*, Asma Saidi, Ayoub Ferradji, Sahra Amel Belambri, Abderrahmane Senator \\ Laboratory of Applied Biochemistry, Faculty of SNV, Department of Biochemistry, University Ferhat Abbas Setif 1, Algeria.
}

\begin{tabular}{|c|c|}
\hline ARTICLE INFO & ABSTRACT \\
\hline Article history: & \multirow{7}{*}{$\begin{array}{l}\text { This study aimed to evaluate the anti-inflammatory activity of alcoholic and aqueous extracts of Pistacia } \\
\text { lentiscus leaves. Croton oil-induced ear edema in mice, acetic acid-induced vascular permeability in mice and } \\
\text { carrageenan induced-pleurisy in rats were conducted as acute inflammation models. Chemotaxis and elastase } \\
\text { activity of human neutrophils were assayed in vitro. Results showed that local treatment with } 2 \text { mg/ear of } \\
\text { alcoholic extract decreased significantly the ear edema }(65 \%) \text {, while the aqueous extract exerted a lower } \\
\text { inhibitory effect }(51 \%) \text {. Moreover, the oral treatment with } 200 \mathrm{mg} / \mathrm{kg} \text { of alcoholic extract inhibited the vascular } \\
\text { permeability by } 46 \% \text {, whereas the aqueous extract caused only } 28 \% \text { of inhibition. Furthermore, both extracts } \\
\text { reduced significant the carrageenan induced-pleurisy. Indeed, at } 400 \mathrm{mg} / \mathrm{kg} \text {, the extracts inhibited the neutrophil } \\
\text { migration by } 29 \% \text { and } 38 \% \text {, respectively, and reduced the number of the PMNS migrated into the pleural } \\
\text { exudates by } 49 \% \text { and } 43 \% \text {, respectively. At } 100 \mu \mathrm{g} / \mathrm{mL} \text {, the methanolic and aqueous extracts inhibited } \\
\text { neutrophil chemataxis by } 81 \% \text { and } 71 \% \text {, respectively, and reduced significantly the elastase activity with } \\
\text { maximum values of } 82 \% \text { and } 90 \% \text {, respectively. These findings provide valuable evidence for the potential } \\
\text { anti-inflammatory of Pistacia lentiscus leaves, suggesting that this plant can be exploited as a natural source of } \\
\text { anti-inflammatory agents. }\end{array}$} \\
\hline Received on: 07/03/2016 & \\
\hline Revised on: 10/05/2016 & \\
\hline Accepted on: 27/05/2016 & \\
\hline Available online: $28 / 07 / 2016$ & \\
\hline Key words: & \\
\hline $\begin{array}{l}\text { Chemotaxis, elastase, } \\
\text { inflammation, neutrophil, } \\
\text { Pistacia lentiscus. }\end{array}$ & \\
\hline
\end{tabular}

\section{INTRODUCTION}

Inflammation is frequently associated with vasodilation and increased vascular permeability, plasma exudation and leukocyte migration to the site of injury. The activation of the biochemical cascade of inflammation causes the release of inflammatory mediators such as cytokines, histamines, kinins, complement factors, clotting factors, nitric oxide, and proteases (Grover et al., 2011). During the early phase (1 - 2h) of the inflammatory response, histamine and serotonin are released from mast cells, starting a cascade of events that produce other mediators such as leukotrienes, prostaglandins and plateletactivating factor (PAF). These factors cause vascular changes leading to plasma exudation and contribute to the establishment

* Corresponding Author

Laboratory of Applied Biochemistry, Faculty of SNV, University

Ferhat Abbas Setif 1, Algeria. E-mail: bouriche_ha@yahoo.fr

Tel: +213776339914 of the acute inflammatory response. During the late phase of the inflammatory process $(4-12 \mathrm{~h})$, the chemoattractant factors induce the recruitment of leukocytes towards the inflammatory site (Cuzzocrea et al., 1998). These cells are triggered to produce inflammatory mediators, which collectively contribute to tissue degradation by activation of several distinct host degradative pathways.

Polymorphonuclear neutrophils (PMNs) are the principal immunity cells which migrate to inflammatory sites, where they release of high quantity of elastase, which plays a key role in bacteria killing and host defense. However, the excessive migration of PMNs into the inflammatory site and the excessive elastase release, which can escape the regulatory systems, are associated with irreversible tissue damage. Elastase is involved in impairing host defense, injuring bronchial epithelial cells, and destroying components of extracellular matrix in lung and contributes to several inflammatory disorders such as acute respiratory distress syndrome and lung emphysema (Houghton, 2015). 
Many medicines of plant origin have been used to treat inflammatory disorders since long time without any adverse effects, and extensive researches prove that many plants represent a source of new compounds with anti-inflammatory activity. Pistacia lentiscus L. (P. lentiscus) belongs to Anacardiaceae family is an evergreen Mediterranean small tree or shrub (ALSaghir and Porter, 2012).

It is a traditional natural remedy that has been used by ancient Mediterranean civilizations. The extract from different parts of this plant shows various activities like antiatherogenic, antioxidant, antimicrobial, antitumor, antiarthritic, antigout, anticancer, hypotensive and antifungal activities (Mohd et al., 2014). Phytochemical studies of $P$. lentiscus extracts revealed the presence of essential oils and phenolic compounds (Bozorgi et al., 2013).

Biological activities of essential oils from $P$. lentiscus fruits are largely studied. However, there are very few studies comparing the anti-inflammatory activity of the extracts from $P$. lentiscus leaves. Hence this study was conducted for the evaluation of the anti-inflammatory activity of $P$. lentiscus leaf extracts using in vivo and in vitro models of inflammation.

\section{MATERIAL AND METHODES}

\section{Chemicals}

Croton oil, indomethacin, $\lambda$-carrageenan, heparin lithium salt, dextran, Hanks' balanced salt solution with $\mathrm{Ca}^{+2}$ and $\mathrm{Mg}^{+2}$ $\left(\mathrm{HBSS}_{2}\right)$ or without $\mathrm{Ca}^{+2}$ and $\mathrm{Mg}^{+2}\left(\mathrm{HBSS}_{1}\right)$, Gallic acid, quercetin, fMet-Leu-Phe (fMLP), Cytochalasine B (CB), Histopaque ${ }^{\circledR}-1077$, HEPES, elastase substrate: MeO-Suc-Ala-Ala-Pro-Val- $p$ nitroanilide, Ovalbumin and Wright stain were supplied by Sigma (Germany). All other reagents were of analytical grade and were supplied by Sigma and Fluka (Germany).

\section{Animals}

Swiss albino mice of either sex weighting 25-30 g and Wistar albino male rats weighing $210-270 \mathrm{~g}$ were used in vivo in this study. These animals were procured from the Pasteur Institute of Algiers, Algeria. All animals were kept to acclimatize under the laboratory conditions for one week and were provided with standard rodent diet and water ad libitum. Animals were randomly selected for different experimental groups (6-7 animal/group) and fasted overnight prior the experiments. All procedures were performed in accordance with European Union Guidelines for Animals Experimentation (2007/526/EC).

\section{Plant material}

Leaves of $P$. lentiscus were collected from Skikda in eastern Algeria, during autumn 2010. The plant was identified and authenticated taxonomically by Pr. H. Laouer, Univesity of Sétif 1, Algeria. A voucher specimen (No. P. L. 2010-1) was preserved in the local Herbarium of Botany, University of Sétif 1 for future reference. The leaves were air-dried at room temperature, reduced to powder and then stored in a paper bags at room temperature away from moisture until use.

\section{Extraction}

Methanolic extract (Met E) was obtained by maceration of $30 \mathrm{~g}$ of the powdered leaves of the plant with $80 \%$ methanolic for $24 \mathrm{~h}$ under continuous shaking at room temperature. After filtration, the filtrate was concentrated under reduced pressure at $40^{\circ} \mathrm{C}$. The residue was lyophilized to give a powder (yield: $16.41 \%)$.

Aqueous extract (Aq E) of $P$. lentiscus leaves was prepared by boiling $25 \mathrm{~g}$ of the powdered leave plant material in $250 \mathrm{~mL}$ of distilled water for $20 \mathrm{~min}$, followed by filtration and centrifugation for $10 \mathrm{~min}$. The supernatant obtained was lyophilized to give a powder (yield: $25.7 \%$ ). Both extracts were stored at $-32{ }^{\circ} \mathrm{C}$ until use.

\section{Determination of total phenolic and flavonoid contents}

Total phenolic content in P. lentiscus extracts was determined using the Folin-Ciocalteu reagent according to Slinkard and Singleton (1977). Gallic acid was used as a standard and the results were expressed as $\mu \mathrm{g}$ of Gallic acid equivalent (GAE)/mg of extract. Flavonoids amount was further estimated by the aluminium trichloride method (Bahorun et al., 1996) using quercetin as standard. Results were expressed as $\mu \mathrm{g}$ of quercetin equivalent $(\mathrm{QE}) / \mathrm{mg}$ of extract.

\section{Croton oil-induced ear edema in mice}

The effect of $P$. lentiscus leaf extracts on Croton-oil induced ear edema was evaluated according to Manga et al. (2004). Briefly, cutaneous inflammation was induced in the inner surface of the right ear of mice (6 mice/group) by application of 15 $\mu \mathrm{l}$ of acetone containing $80 \mu \mathrm{g}$ of Croton oil as irritant. Treated animals received topically $2 \mathrm{mg} / \mathrm{ear}$ of extract or $0.5 \mathrm{mg} / \mathrm{ear}$ of indomethacin, used as reference drug. The control animals received only the irritant agent. The thickness of ears was measured before and $6 \mathrm{~h}$ after induction of inflammation using a dial calipers. The edema was expressed as an increase in the ear thickness due to Croton oil application.

\section{Acetic acid-induced vascular permeability in mice}

The effect of $P$. lentiscus leaf extracts on vascular permeability was evaluated according to the method of Kou et al. (2006) with slight modifications. The treated mice (7 mice/group) received orally $0.2 \mathrm{~mL}$ of either $200 \mathrm{mg} / \mathrm{kg}$ of the Met E, Aq E or $50 \mathrm{mg} / \mathrm{kg}$ indomethacin. The control group received the same volume $(0.2 \mathrm{~mL})$ of vehicle orally. One hour later, $10 \mathrm{mg} / \mathrm{kg}$ of $1 \%$ $(w / v)$ Evan's blue was injected intravenously through the tail vain followed by intra-peritoneal injection of $10 \mathrm{~mL} / \mathrm{kg}$ of $0.7 \%$ acetic acid. Thirty minutes later, the mice were sacrificed by cervical dislocation and the peritoneal exudates were collected after being washed with $3 \mathrm{~mL}$ of normal saline, and centrifuged at $2000 \mathrm{rpm}$ for $10 \mathrm{~min}$. The absorbance of the supernatant was read at $610 \mathrm{~nm}$. The dye content of the exudates, which refers to the rate of 
vascular permeability, was calculated according to the standard curve of Evans Blue.

\section{Carrageenan induced-pleurisy in rats}

The effect of $P$. Lentiscus extracts on carrageenan induced-pleurisy in rats was conducted according to Cuzzocrea et al. (2000). Treated rats (7 rats/group) were administered orally 2 $\mathrm{mL}(400 \mathrm{mg} / \mathrm{kg})$ of alcoholic or aqueous extract of $P$. lentiscus leaves, one hour before the intra-pleural injection of $0.2 \mathrm{~mL}$ of $\lambda$ carrageenan $(1 \%)$. Rats of the positive control group were treated orally with $2 \mathrm{~mL}$ of saline solution. Animals were lightly anaesthetized with chloroform and submitted to a skin incision at the level of the left sixth intercostal space. The underlying muscle was dissected and saline solution $(0.2 \mathrm{~mL})$ containing $1 \% \lambda$ carrageenan $(0.2 \mathrm{~mL})$ was injected into the pleural cavity. Rats of negative control group were injected in their pleural cavity $0.2 \mathrm{~mL}$ of sterile $0.9 \% \mathrm{NaCl}$ instead of the $\lambda$-carrageenan solution and were not treated with any other substance. The skin incision was closed with a suture and the animals were allowed to recover. Four hours after the injection of $\lambda$-carrageenan, rats were killed and their chests were carefully opened, the pleural cavity is subsequently washed with $2 \mathrm{~mL}$ of heparinized saline solution. The exudate and washing solution were removed by aspiration and the total volume was measured. Any exudate, which was contaminated with blood, was discarded. The amount of exudates was calculated by subtracting the volume injected $(2 \mathrm{~mL})$ from the total volume recovered. The leukocytes in the exudate were suspended in PBS and counted with an optical microscope after vital Trypan blue staining.

\section{Human neutrophil isolation and cell viability}

Human isolated neutrophils as a cellular model were used to evaluate the ex vivo immunomodulatory effect of $P$. lentiscus extracts. These cells were isolated from freshly heparinized $(5 \mathrm{U} / \mathrm{mL})$ blood of healthy volunteers as previously described (Selloum et al., 2003). Briefly, PMN isolation was carried out by centrifugation on a Ficoll-Hipaque ${ }^{\circledR}$ gradient density after a dextran-enhanced sedimentation. The remaining red blood cells were eliminated by hypotonic lysis. PMNs were preserved in $\mathrm{HBSS}_{1}$ and kept on ice until use. This method routinely yielded cells that were $\geq 95 \%$ viable neutrophils as assessed by trypan blue exclusion test. The Trypan blue exclusion test is widely used to measure plasma membrane integrity. Therefore, it was used to assess the effects of the extracts on cell viability. Cells were incubated for $30 \mathrm{~min}$ with different concentrations $(20-200$ $\mu \mathrm{g} / \mathrm{mL}$ ) of $P$. lentiscus leaf extracts, and then they were incubated with trypan blue $(0.4 \%)$ for $10 \mathrm{~min}$ and the resulting percentage of blue cells, indicating a capture of the colorant due to plasma membrane rupture, were counted. Normal cell viability was considered to be between $90 \%-95 \%$.

\section{Neutrophil chemotaxis assay}

In order to evaluate the immunomodulatory effect of $P$. lentiscus alcoholic and aqueous extracts, neutrophil chemotaxis was assayed in 48-microwell chemotaxis chamber (Neuroprobe, Inc., USA) using a $5 \mu \mathrm{m}$ pore size polycarbonate filter according to Falk et al. (1980). PMNs $\left(1.5 \times 10^{6}\right.$ cells $\left./ \mathrm{mL}\right)$ suspended in $\mathrm{HBSS}_{2}$ supplemented with $0.25 \%$ ovalbumine were pre-incubated for 10 min at $37^{\circ} \mathrm{C}$ with various concentrations $(20-100 \mu \mathrm{g} / \mathrm{mL})$ of $P$. lentiscus extracts, then placed in the upper wells of the chemotaxis chamber.

Cells were then allowed to migrate towards fMLP $\left(10^{-7}\right.$ M) present in the lower wells for $90 \mathrm{~min}$ at $37^{\circ} \mathrm{C}$ in a humidified atmosphere containing $\mathrm{CO}_{2} 5 \%$. After incubation, the filter was removed, fixed in absolute methanolic and stained with Wright's stain. Positive control (absence of extracts) and negative control (only medium in the lower wells) are conducted in parallel with experimental samples. Neutrophils that had migrated trough the filter were counted under light microscopy at $\times 400$ magnification in five random fields for each of three replicate wells. A mean value was obtained for each well. The average number of cell migration in the negative control wells was subtracted as background from the number migrating in test wells, to yield the net number of neutrophils migrating per field. Each experiment was repeated at least three times.

\section{Determination of elastase activity}

Neutrophil elastase activity assay was conducted to study the immunomodulatory effect of $P$. lentiscus extracts. Briefly, the elasase activity was determined in cell released supernatant, according to the method of Bieth et al. (1980). Elastase was produced by the incubation of PMNs suspension $\left(5 \times 10^{6}\right.$ cells $\left./ \mathrm{mL}\right)$ for $20 \mathrm{~min}$ at $37^{\circ} \mathrm{C}$ in the presence of $\mathrm{fMLP} / \mathrm{CB}\left(10^{-5} \mathrm{M}\right)$. Thereafter, elastase rich supernatant aliquots were treated with different concentrations of $P$. lentiscus extract $(20-100 \mu \mathrm{g} / \mathrm{mL})$ or $\mathrm{HBSS}_{1}$ (Control). On a microtitration plate well, $75 \mu \mathrm{l}$ of the treated and untreated supernatant were mixed with $75 \mu$ of the elastase synthetic substrate, $\quad N \mathrm{MeO}-S u c-(A l a)_{2}$-Pro-Val- $p$ nitroanilide $\left(5 \times 10^{4} \mathrm{M}\right)$, which was dissolved in a HEPES medium (0.1 M; pH 7.4). After incubation for $40 \mathrm{~min}$ at $37^{\circ} \mathrm{C}$, the formation of the $p$-Nitroanilide product was quantified at $405 \mathrm{~nm}$ using microplate reader (Stat Fax 2100, USA). Results were expressed as the percentage of elastase activity inhibition compared with the control considered as $100 \%$ of activity.

\section{STATISTICAL ANALYSIS}

Results are expressed as mean \pm SEM. Statistical analysis was performed using one-way analysis of variance (ANOVA) and $t$-test Student. The differences between the control and samples were considered statistically significant at $p \leq 0.05$.

\section{RESULTS}

\section{Total phenolic and flavonoid contents}

The quantitative estimation of total phenolic and flavonoid in the P. lentiscus leaf extracts showed that methanolic extract is richer in polyphenols and flavonoids than aqueous extract (Table 1). 
Table 1: Total phenolic and flavonoid contents in P. lentiscus leaf extracts.

\begin{tabular}{lcc}
\hline Extract & $\begin{array}{c}\text { Polyphenols } \\
\boldsymbol{\mu g} \text { of GAE/mg of } \\
\text { extract }\end{array}$ & $\begin{array}{c}\text { Flavonoids } \\
\boldsymbol{\mu g} \text { of QE/mg of } \\
\text { extract }\end{array}$ \\
\hline Met E & $268 \pm 0.7$ & $15 \pm 0.06$ \\
Aq E & $227 \pm 0.3$ & $11 \pm 0.1$ \\
\hline Data are expressed as mean \pm SEM $(\mathrm{n}=3)$. &
\end{tabular}

\section{Effect of $P$. lentiscus leaf extracts on Croton-oil induced ear edema}

Six hours after the topical application of the irritating agent, the mice in the control group developed an edema at their right ears with a thickness of $112 \pm 22 \mu \mathrm{m}$. The local treatment of mice by $2 \mathrm{mg}$ of alcohol extract of $P$. lentiscus leaves decreased significantly $(\mathrm{p}<0.001)$ the inflammation compared to the control group mice. The ear thickness was $39 \pm 9 \mu \mathrm{m}$, which corresponds to $65 \%$ of inhibition. This inhibition is greater than that obtained with indomethacin, which exhibited an inhibition of $54 \%$. The effect exerted by the aqueous extract $(51 \%)$ is very close to that of indomethacin (Fig. 1).

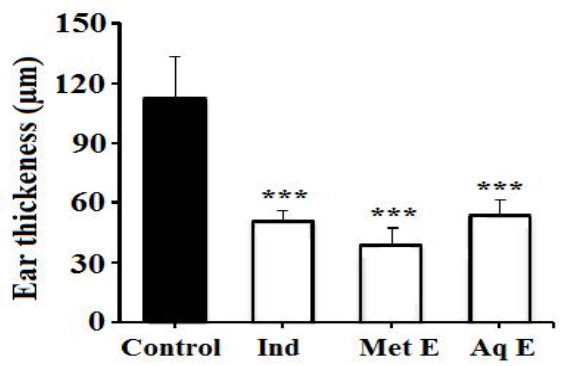

Fig. 1: Effect of P. lentiscus extracts on Croton oil induced-ear edema in mice. Mice were treated with $2 \mathrm{mg} /$ ear of methanolic extract (Met $\mathbf{E}$ ), aqueous extract (Aq E) or $0.5 \mathrm{mg} /$ ear of indomethacin (Ind). Control group received sterile saline solution only. Edema is expressed as mean thickness of ears before and $6 \mathrm{~h}$ after Croton oil application. Values are expressed as means \pm SEM $(\mathrm{n}=6)$. ***: $p<0.001$ vs control.

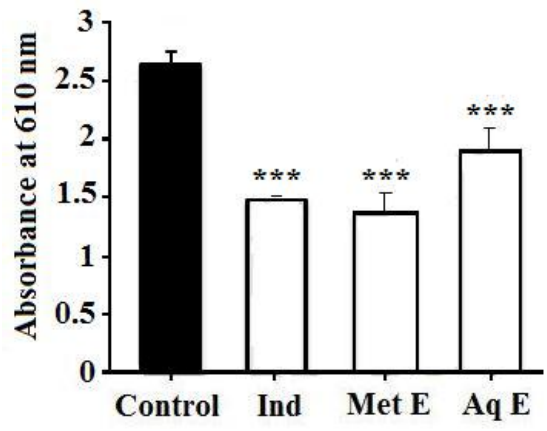

Fig. 2: Effect of $P$. lentiscus extracts on vascular permeability induced by acetic acid in mice. Animals were pre-treated orally with $200 \mathrm{mg} / \mathrm{kg}$ of methanolic extract (Met E), aqueous extract (Aq E) or $50 \mathrm{mg} / \mathrm{Kg}$ of indomethacin (Ind). Control group received only saline solution. Values are expressed as means $\pm \operatorname{SEM}(\mathrm{n}=7)$. ${ }^{* * *} P<0.001$ vs control.

\section{Effect of $P$. lentiscus extracts on acetic acid-induced vascular permeability}

Results showed that treatment with alcohol or aqueous extract of $P$. lentiscus leaves or indomethacin, one hour before the induction of inflammation with acetic acid, inhibited significantly $(p<0.001)$ the vascular permeability. Indeed, treatment by 200 $\mathrm{mg} / \mathrm{kg}$ of methanolic extract reduced the vascular permeability by $(46 \%)$. This effect is better than that obtained with $50 \mathrm{mg} / \mathrm{kg}$ of indomethacin (44\%). In contrast, aqueous extract exerted only $28 \%$ of inhibition (Fig. 2).

\section{Carrageenan induced-pleurisy}

Rats of the negative control injected with sterile saline solution did not produce any exudate in their pleural cavity. The exudate volume represents only $6 \%$ compared to the volume produced by the rats of the positive control group (Fig. 3). Further, the infiltration of PMNs into the pleural cavity of negative control rats is also very low $\left(4 \pm 1.4 \times 10^{6}\right.$ PMNs/exudate), or approximately $6 \%$ compared to the number of PMNs recovered from the positive control group rats $\left(66 \pm 5 \times 10^{6} \mathrm{PMNs} /\right.$ exudate $)$ (Fig. 4).

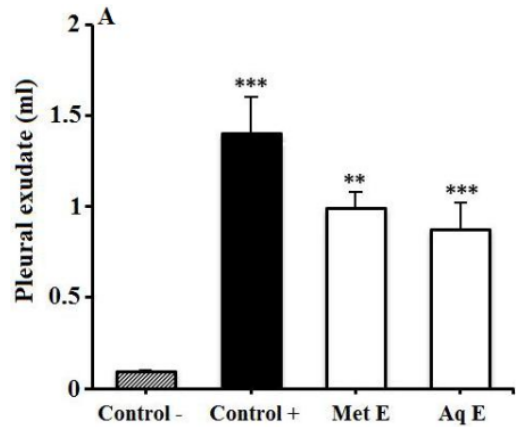

Fig. 3: Effect of $P$. lentiscus leaf extracts on the Volume of exudate in $\lambda$ carrageenan-induced pleurisy in the rats. Rats were pretreated orally with 200 $\mathrm{mg} / \mathrm{kg}$ methanolic (Met E) or aqueous (Aq E) extracts. The positive control $($ control +$)$ was pretreated with normal saline solution and then injected by $\lambda$ carrageenan, while the negative control (control-) without injection of $\lambda$ carrageenan, received only saline solution. TheVolume of exudate aspirated from the pleural cavity $4 \mathrm{~h}$ after the injection of $\lambda$-carrageenan. Results are expressed as mean $\pm \operatorname{SEM}(\mathrm{n}=7)$. $* * * P<0.001 ; * * P<0.05$ vs positive control.

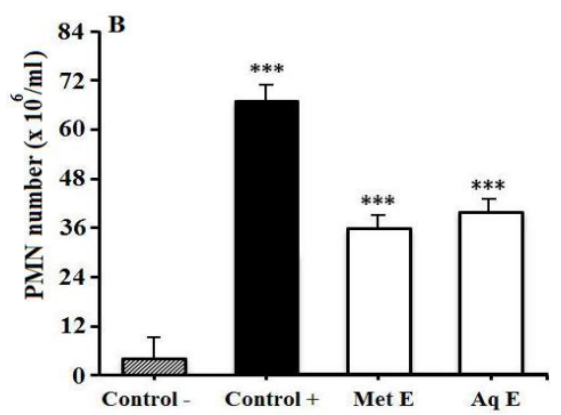

Fig. 4: Effect of $P$. lentiscus leaf extracts on the number of PMNs migrated into exudates $4 \mathrm{~h}$ after the injection of $\lambda$-carrageenan. Rats were pretreated orally with $200 \mathrm{mg} / \mathrm{kg}$ methanolic (Met E) or aqueous (Aq E) extracts. The positive control (control + ) was pretreated with normal saline solution and then injected by $\lambda$-carrageenan, while the negative control (control-) without injection of $\lambda$-carrageenan, received only saline solution. TheVolume of exudate aspirated from the pleural cavity $4 \mathrm{~h}$ after the injection of $\lambda$ carrageenan. Results are expressed as mean \pm SEM $(\mathrm{n}=7)$. ***: $P<0.001 \mathrm{vs}$ positive control.

Oral administration of $400 \mathrm{mg} / \mathrm{kg}$ of methanolic or aqueous extract of $P$. lentiscus decreased significantly $(p<0.001)$ the development of pleurisy. Indeed, the methanolic extract inhibited the exudation by $29 \%$ compared with the rats of the 
positive control group (Fig. 3), and exerted $49 \%$ of inhibition on the number of PMNs migrated into the exudates (Fig. 4). Furthermore, the aqueous extract exerted an inhibitory effect of $38 \%$ on the volume of the exudates (Fig. 3), and reduced the number of the PMNS migrated into the exudates by $43 \%$. The number of PMNs present in the exudate, was only $37.66 \pm 3 \times 10^{6}$ PMNs/rat (Fig. 4).

\section{Effect of $\boldsymbol{P}$. lentiscus extracts on neutrophil chemotaxis}

The chemoattractant fMLP activated strongly the chemotaxis response of isolated neutrophils. Indeed, in the presence of $10^{-7} \mathrm{M}$ of fMLP the number of transmigrated PMNs (74 \pm 4 cells/field) was 3 times more than that in the absence of fMLP. P. lentiscus extracts inhibited significantly $(p<0.05)$ and in a dose-dependent manner the fMLP-stimulated neutrophils chemotaxis. At $100 \mu \mathrm{g} / \mathrm{mL}$, the methanolic and aqueous extracts inhibited PMN migration by $81 \%$ and $71 \%$, respectively (Fig. 5). The $\mathrm{IC}_{50}$ values were $19.8 \pm 0.8$ and $26.7 \pm 0.7$, respectively.

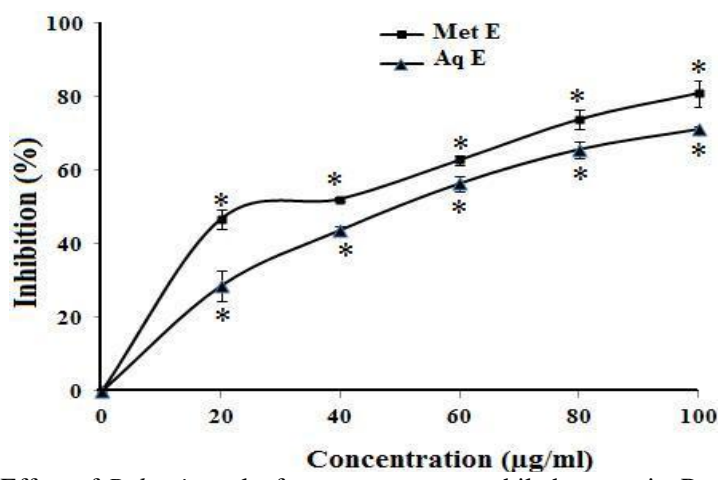

Fig. 5: Effect of $P$. lentiscus leaf extracts on neutrophil chemotaxis. Results are expressed as the percentage of neutrophils migrating per field compared with the positive control (without treatment) set to $100 \%$. Values represent the mean \pm SEM of 3 independent experiments each performed in triplicate. ${ }^{*} p<0.05$ vs control.

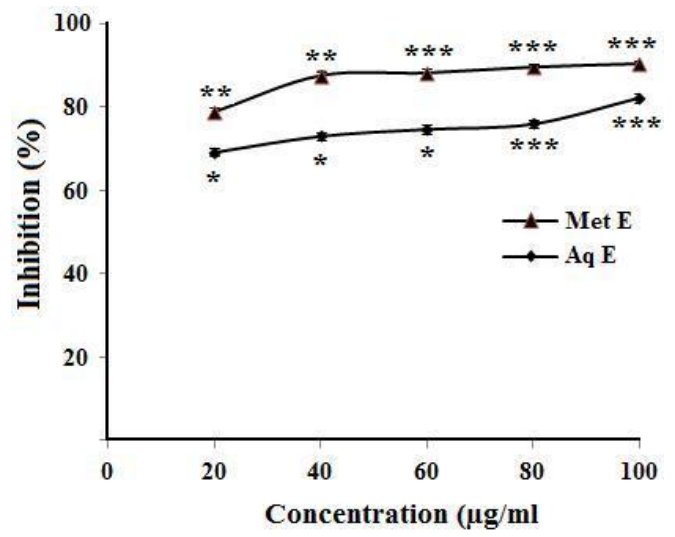

Fig. 6: Effect of P.lentiscus extracts on the human neutrophil elastase activity. Results are expressed as inhibitory percentage of elastase activity compared to the positive control (untreated elastase) set at $100 \%$. Values represent the mean \pm SEM of 3 independent experiments. ${ }^{*} p<0.05$, ** $p<0.01$, *** $p<$ 0.001

\section{Effect of $P$. lentiscus extracts on elastase activity}

Results revealed that methanolic and aqueous extracts of P. lentiscus inhibited significantly $(p<0.01)$ the elastase activity
(Fig. 6). This inhibition remained stable with maximum values of $82 \%$ and $90 \%$, respectively.

\section{DISCUSSION}

Anti-inflammatory and immunomodulatory properties of Pistacia lentiscus leaf extracts were evaluated in the current study, using different experimental models that could provide different mechanisms underlying the anti-inflammatory activities of this plant. Ear edema induced by Croton oil is a wide used model to study the inflammatory processes, as well as identifying new antiinflammatory compounds. In this model, edema events are triggered by protein kinase $\mathrm{C}$ (PKC), which leads to $\mathrm{PLA}_{2}$ activation and then the release of arachidonic acid from membrane phospholipids. Arachidonic acid is subsequently metabolized by cyclooxygenase (COX) and lipooxygenase (LOX) to generate a variety of bioactive eicosanoids, including prostaglandins and leukotriene, which are implicated in the development of inflammatory conditions. PKC also promotes various immune mediators such as cytokines and chemokines that increase and maintain the inflammatory response (Kim et al. 2013). Local pretreatment of ear mice with $P$. lentiscus alcohol and aqueous extracts reduced significantly the size of the ear edema. The presence of phenolic compounds in these extracts might be partly responsible for this effect. Indeed, $P$. lentiscus leaf extracts contain important quantities of flavonoids and gallic acid (Bozorgi et al., 2013). Furthermore, Bendifallah et al. (2014) affirmed the richness of $P$. lentiscus leaf extracts with the condensing tannin precursors. Flavonoids such as quercetin and myricetin exert a strong inhibition on COX and LOX (Kutil et al., 2014). Gallic acid and its derivatives are responsible for the inhibition of p38 mitogenactivated protein kinase (MAPK) activation and inhibition of NF$\mathrm{kB}$ activation (Ahad et al., 2015), which are essential for histamine release and pro-inflammatory cytokine expression such as TNF- $\alpha$ and IL-6. The decrease in ear swelling is also probably due to the antioxidant effects of the extracts, since reactive oxygen species produced during inflammation by phagocytic cells and during the arachidonic acid metabolism may activate phospholipase A2 . Indeed, P. lentiscus extracts exhibit a good antioxidant effect (Remila et al., 2015).

During acetic acid induced-vascular permeability model, the increase of serotonin, histamine, PAF and, leukotrienes and prostaglandins lead to a dilation of arterioles and venules thereby increase the vascular permeability. As a consequence, fluid and plasma protein are extravasated and edema is formed (Cuzzocrea et al., 1998). Pre-treatment with P. lentiscus extracts inhibited significantly the vascular permeability in mice, which indicates that these extracts are able to control the amplification of the inflammatory response. The presence of anthocyanins, flavonoids and tannins in P. lentiscus leaf extracts may contribute to this antiinflammatory effect. Indeed, it has been reported that anthocyanins reduce nuclear factor- $\kappa \mathrm{B}(\mathrm{NF}-\kappa \mathrm{B})$ transactivation and decreased plasma concentrations of pro-inflammatory chemokines, cytokines, and inflammatory mediators (Karlsen et al., 2007). 
Flavonoids have been found to have anti-inflammatory activity in both proliferative and exudative of inflammation phases, they inhibit histamine, cytokine, prostaglandins and leukotrienes release (Park, 2008; Permender et al., 2009). Furthermore, in vitro and in vivo assays indicated that hydrolysable tannins are a very effective treatment against inflammatory disorders (Ismail et al., 2012).

The plasma exudation and the infiltration of PMNs into the pleural cavity exudates of rats, during the first 4 hours following the induction of pleurisy by $\lambda$-carrageenan has been exploited in this study to evaluate the anti-inflammatory effect in vivo of alcohol and aqueous $P$. lentiscus leaf extracts. Oral administration of these extracts significantly attenuated the development of pleurisy, by inhibiting plasma exudation as well as leukocyte recruitment to the inflated site. This result indicates that $P$. lentiscus leaf extracts are able to reduce the production of inflammatory mediators involved in the development of the acute inflammatory reaction. In fact, alcohol and aqueous $P$. lentiscus leaf extracts are rich in flavonoids and polyphenols. These compounds are good inhibitors of serotonin, histamine and leukocyte migration by blocking their adhesion to the vascular wall. It has been reported that quercetin blocks adhesion of leukocytes to the endothelial wall of the umbilical veins by inhibiting the expression of ICAM-1 (Middleton et al., 2000), while Gallic acid inhibits leukocyte migration by inhibiting the adhesion molecule VCAM-1, ICAM-1 and E-selectin in vascular endothelial cells (Triantafyllou et al., 2011). This inhibition is due to the inhibition of the synthesis of IL- 1 and TNF- $\alpha$ major inducers of the expression of adhesion molecules on the vascular wall (Calixto et al., 2004). In addition, cyanidin 3-O-betaglucoside reduced the increase of mediators induced neutrophil migration, such as NO, TNF- $\alpha$, IL- $1 \beta$ and normalizes the levels of several acute phase proteins (Calixto et al., 2004).

The modulation of immune cell activities is of active interest for the treatment of inflammation. Therefore, many immunological studies used the human isolated neutrophils as a cellular model to evaluate the ex vivo effect of immunomodulatory drugs on the PMNs excessive activation. In the present study, the immunomodulatory activity of $P$. lentiscus extracts was carried out by neutrophil migration and elastase release tests. The results showed that $P$. lentiscus extracts inhibited significantly the fMLPstimulated neutrophils chemotaxis and elastase activity. Under our experimental conditions, $P$. lentiscus leaf extracts were not toxic to PMNs as assessed by trypan blue exclusion test. Therefore, the extract activities could not be due to the cytotoxicity effect. The immunomodulatory activities of medicinal plants were associated extremely to their contents of flavonoid and phenolic compounds. In this context, Selloum et al. (2003) reported that the natural flavonol, rutin, exerted a significant inhibitory effect on the human PMNs migration induced by the AMLP, while Souto et al. (2011) reported that quercetin acts as a potent chemotaxis inhibitor. Moreover, Liu et al. (2012) showed that flavonoids such as quercetin, myricetin and genistein could inhibit the PI3-kinase, which involved in neutrophil response signaling pathways. On the other hand, Sartor et al. (2002) revealed that the group glycosidic of flavones can affect the steric conformation of the elastase and lead to interactions enzyme-phenols, consequently the inhibition of its proteolytic activity. However, Piwowarski et al. (2011) demonstrated that the anti-elastase effect of tannin-rich plant is due to its ability to bind the enzymatic protein, which cause protein precipitation.

\section{CONCLUSION}

Pistacia lentiscus leaf extracts exerted a potent antiinflammatory effect by inhibiting different phases of inflammation. So, this plant can constitute a promising natural source of bioactive compounds that give significant antiinflammatory properties.

\section{CONFLICT OF INTEREST}

The authors declare that there is no conflict of interest.

\section{ACKNOWLEDGEMENTS}

The authors are thankful to the Algerian Ministry of high education for the financial support.

\section{REFERENCES}

Ahad A, Ahsan H, Mujeeb M, Siddiqui WA. Gallic acid ameliorates renal functions by inhibiting the activation of p38 MAPK in experimentally induced type 2 diabetic rats and cultured rat proximal tubular epithelial cells. Chem Biol Interact, 2015; 5: 292-303.

AL-Saghir MG, Porte DM. Taxonomic revision of the Genus Pistacia L. (Anacardiaceae). Am J Plant Sci, 2012; 3: 12-32.

Bahorun T, Gressier B, Trotin F, Brunet C, Dine T, Luyckx M, Vasseur J, Cazin M, Cazin JC, Pinkas M. Oxygen species scavenging activity of phenolic extracts from hawthorn fresh plant organs and pharmaceutical preparations. Arzneimforsch, 1996; 46: 1086-1089.

Bendifallah L, Benmahfoud AE, Hameni Y, Mameche S. Phytochemical study and antibacterial of Pistacia lentiscus L. in Boumerdes mountainous region (Algeria) J Fundament Appl Sci; 2014; 6 , 229-237.

Bieth J, Spiess B, Wermuth CG. The synthesis and analytical use of a highly sensitive and convenient substrate of elastase. Biochem Med, 1974; 11: 350-357.

Bozorgi M, Memariani Z, Mobli M, Hossein M, Surmaghi MHS, Shams-Ardekani MR, Roja R. 2013. Five Pistacia species ( $P$. vera, $P$. atlantica, $P$. terebinthus, $P$. khinjuk, and $P$. lentiscus): A Review of Their Traditional uses, phytochemistry, and pharmacology. Sci World J, 2013. [ONLINE] Available at: http://dx.doi.org/10.1155/2013/219815

Calixto JB, Campos MM, Otuki MF, Santos AR. Antiinflammatory compounds of plant origin. Part II. modulation of proinflammatory cytokines, chemokines and adhesion molecules. Planta Med; 2004; 70: 93-103.

Cuzzocrea S, Zingarelli B, Hake P, Salzman AL, Zabo C. Antiinflammatory effects of mercaptoethylguanidine, a combined inhibitor of nitric oxide synthase and peroxynitrite scavenger, in carrageenan-induced models of inflammation. Free Radic Biol Med, 1998; 24: 450-459.

Cuzzocrea S, Santagati S, Sautebin L, Mazzon E, Calabro G, Serraino I, Caputi AP, Maggi A. 17 $\beta$-Estradiol anti-inflammatory activity in carrageenan-induced pleurisy. Endocrinology; 2000; 141: 1455-1463.

Falk W, Goodwin RHJR, Leonard EJ. A 48-Well microchemotaxis assembly for rapid and accurate measurement of leukocyte migration. J Immunol Methods, 1980; 33: 239-247. 
Grover S, Srivastava A, Lee R, Tewari AK. Role of inflammation in bladder function and interstitial cystitis. Ther Adv Urol, 2011; 3: 19-33.

Houghton AM. Matrix metalloproteinases in destructive lung disease. Matrix Biol, 2015; 44: 167-174.

Ismail T, Sestili P, Akhtar S. Pomegranate peel and fruit extracts: A review of potential anti-inflammatory and anti-infective effects. J Ethnopharmacol, 2012; 143: 397-405.

Karlsen Anette, Retterst $\varnothing 1$ L, Laake P, Paur I, Kjølsrud Bøhn S, Sandvik L, Blomhoff R. Anthocyanin inhibits NF- $\kappa$ B transactivation and deceased plasma concentrations of pro-inflammatory chemokines, cytokines, and inflammatory mediators. J Nutr, 2007; 137: 1951-1954.

Kim H, Zamel R, Bai X-H, Liu M. PKC Activation Induces Inflammatory Response and Cell Death in Human Bronchial Epithelial Cells. PLoS One, 2013; 18: e64182, doi: 10.1371/journal.pone.0064182.

Kou J, Si M, Dai G, Lin Y, Zhu D. Anti-inflammatory activity of Polygala japonica extract. Fitoterapia, 2006; 77: 411-415.

Kutil Z, TemmL V, Maghradze D, Pribylova M, Dvorakova M, Schuster D, Vanek T, Landa P. 2014. Impact of wines and wine constituents on cyclooxygenase-1, cyclooxygenase-2, and 5-lipoxygenase catalytic activity. Mediators Inflamm. 2014. [ONLINE] Available at: http://dx.doi.org/10.1155/2014/178931

Liu J, Hu Y, Waller DL, Wang J, Liu Q. Natural products as kinase inhibitors. Nat Prod Rep, 2012; 29: 392-403.

Manga HM, Brkic D, Marie DEP, Quetin-Leclercq J. In vivo anti-inflammatory activity of Alchornea cordifolia (Schumach. \& Thonn.) Müll. Arg. (Euphorbiaceae). J Ethnopharmacol, 2004; 92: 209-214.

Middleton E Jr, Kandaswami C, Heoradies TC. The effects of plant flavonoids on mammalian cells: Implications for inflammation, heart disease, and cancer. Pharmacol Rev, 2000; 52: 673-751.

Mohd A, Hamid A, Kamal A, mushtaq H, mehboob A. Mastagi (Pistacia lentiscus) a Unani medicine: a review. Univ J Pharm,2014; 3: $46-50$.

Park HH, Lee S, Son HY, Park SB, Kim MS, Choi EJ, Singh TS, Ha JH, Lee MG, Kim JE, Hyun MC, Kwon TK, Kim YH, Kim SH. Flavonoids inhibit histamine release and expression of proinflammatory cytokines in mast cells. Arch Pharm Res, 2008; 31: 1303-11.
Permender, R., Hema, C., Sushila, R., Harmender, R., Vikash, K., Kanchan, K., 2009. Mechanism of action of flavonoids as antiinflammatory agents: A review. Source. Inflamm. Allergy Drug Targets. 8, 229-235.

Piwowarski, J.P., Kiss, A.K., Kozlowska-Wojciechowska, M., 2011. Anti-hyaluronidase and anti-elastase activity screening of tanninrich plant materials used in traditional Polish medicine for external treatment of diseases with inflammatory background. J. Ethnopharmacol. 137, 937-941.

Sartor L, Pezzato E, Dell'Aica I, Caniato R, Biggin S, Garbisa S. Inhibition of matrix-proteases by polyphenols: chemical insights for anti-inflammatory and invasion drug design. Biochem Pharmacol, 2002; 64: 229-237.

Remila S, Atmani-Kilani D, Delemasure S, Connat J-L, Azib L, Richard T, Atmani D. Antioxidant, cytoprotective, anti-inflammatory and anticancer activities of Pistacia lentiscus (Anacardiaceae) leaf and fruit extracts. Eur J Integr Med, 2015; 7: 274-286.

Selloum L, Bouriche H, Tigrine C, Boudoukha C. Antiinflammatory effect of rutin on rat paw edema, and on neutrophils chemotaxis and degranulation. Exp Toxicol Pathol, 2003; 54: 313-318.

Slinkard K, Singleton VL. Total phenol analysis: automation and comparison with manual methods. Am J Enol Vitic, 1977; 28: 45-55.

Souto FO, Zarpelon AC, Staurengo-Ferrari L, Fattori V, Casagrande R, Fonseca MJ, Cunha TM, Ferreira SH, Cunha FQ, Verri WAJr. Quercetin reduces neutrophil recruitment induced by CXCL8, LTB4, and fMLP: inhibition of actin polymerization. J Nat Prod, 2011. 2011; 74: 113-118.

Triantafyllou A, Bikineyeva A, Dikalova A, Nazarewicz R, Lerakis S, Dikalov S. Anti-inflammatory activity of Chios mastic gum is associated with inhibition of TNF-alpha induced oxidative stress. Nutr J, 2011; 10: 64-73.

\section{How to cite this article:}

Bouriche H, Saidi A, Ferradji A, Belambri SA, Senator A. Antiinflammatory and immunomodulatory properties of Pistacia lentiscus extracts. J App Pharm Sci, 2016; 6 (07): 140-146. 